\title{
Determinación microbiológica y molecular mediante PCR en tiempo real de dos bacterias del género Bacillus de interés agro biotecnológico
}

\author{
Microbiological and molecular determination by real-time PCR of two bacteria of the genus \\ Bacillus of agro biotechnological interest
}

Viviana Chiluisa-Utreras ${ }^{1 *}$, Michelle Campaña Verdesoto², Ramiro Daniel Acurio ${ }^{1}$

DOI. 10.21931/RB/2020.05.02.4

Resumen: Se efectuó la comparación de curvas de crecimiento a diferentes rangos de pH, salinidad y temperatura, además se determinó el tamaño, forma y posición de endospora de dos diferentes cepas del género Bacillus. Para la identificación molecular se realizó la extracción de ácidos nucleicos, utilizando el kit High Pure PCR Template Preparation Kit de Roche ${ }^{\circledR}$ y posteriormente se analizaron las curvas de amplificación producto de la PCR en Tiempo Real.

Se realizaron cinéticas de crecimiento a cada uno de los cultivos de bacterias durante 72 horas y se analizaron estadísticamente las curvas mediante los métodos estadísticos ANOVA y Tukey para determinar significancia $(p<0.001)$. El análisis factorial para la variable "temperatura" no mostró una diferencia significativa entre cepas y tampoco con los valores fijados $\left(28,32,37^{\circ} \mathrm{C}\right)$, la variable "pH" si presentó una interacción con valores ( $p<0.0001)$ entre cepas; la variable "salinidad" también presentó diferencia significativa entre cepas y con sus respectivas interacciones. En el análisis del área bajo la curva, la variable "temperatura" no mostró diferencia significativa, mientras que las variables "pH y salinidad" presentaron valores correspondientes a $(p<0.0001)$. Para la determinación molecular, se analizaron las curvas de amplificación, confirmando la presunción bioquímica de la cepa BM como B. megaterium mediante el análisis del gen phaC, así como también se pudo corroborar que la cepa BL corresponde a $B$. licheniformis al analizar el gen lchAA. La cinética bacteriana permitió establecer las horas clave para el análisis del crecimiento, confirmando que las características analizadas corresponden a especies pertenecientes a la familia Bacillaceae, con aplicación como controladores biológicos en la agricultura.

Palabras clave: B. Licheniformis, B. megaterium, gen lchAA, gen phaC, PCR en Tiempo Real.

Abstract: The comparison of growth curves was carried out at different ranges of $\mathrm{pH}$, salinity, and temperature, and the size, shape, and position of the endospore of two different strains of the genus Bacillus were also determined. For molecular identification, nucleic acid extraction was performed using the Roche ${ }^{\circledR}$ High Pure PCR Template Preparation Kit and the amplification curves resulting from Real-Time PCR were subsequently analyzed.

Growth kinetics were performed on each of the bacteria cultures for 72 hours and the curves were statistically analyzed using the statistical methods ANOVA and Tukey to determine significance $(p<0.001)$. The factorial analysis for the variable "temperature" did not show a significant difference between strains and neither with the fixed values $\left(28,32,37^{\circ} \mathrm{C}\right)$, the variable "pH" did show an interaction with values $(p<0.0001)$ between strains; the variable "salinity" also presented a significant difference between strains and with their respective interactions. In the analysis of the area under the curve, the variable "temperature" did not show a significant difference, while the variables "pH and salinity" presented values corresponding to $(\mathrm{p}<0.0001)$. For molecular determination, the amplification curves were analyzed, confirming the biochemical presumption of the BM strain as $B$. megaterium through the analysis of the phaC gene, as well as it was possible to corroborate that the $\mathrm{BL}$ strain corresponds to $B$. licheniformis when analyzing the gene. IchAA. Bacterial kinetics allowed establishing the key hours for growth analysis, confirming that the characteristics analyzed correspond to species belonging to the Bacillaceae family, with the application as biological controllers in agriculture.

Key words: B. Licheniformis, B. megaterium, LchAA gene, phaC gene, Real-time PCR.

\section{Introducción}

El género Bacillus forma parte de la familia Bacillaceae, está compuesto por bacilos gram positivos grandes, caracterizados por su capacidad de producir endosporas ${ }^{1}$. El género incluye microorganismos aerobios estrictos y anaerobios facultativos; algunas especies son parásitas o patógenas para animales, principalmente insectos, ya que crecen bien en los medios comunes, fermentan carbohidratos y descomponen proteínas. Las técnicas microbiológicas brindan información sobre la morfología de las colonias, la cual es fundamental en la identificación preliminar para la diferenciación de los microorganismos, la observación del fenotipo permite ubicarlo dentro del género Bacillus, pero muchas veces no resulta

suficiente para una determinación precisa. Por esto, se acuden a técnicas más sofisticadas, como los ensayos moleculares basados en el análisis del genotipo de los microorganismos, que proporcionan información más específica al momento de hacer una amplificación². La presente investigación se llevó a cabo con el objetivo principal de identificar bacterias de interés agro biotecnológico, que presentan presunción bioquímica dentro del género Bacillus. Para efectuar la presente investigación se reactivaron dos cepas crio conservadas, se determinó la concentración inicial de las muestras mediante la técnica McFarland junto con la comparación de curvas de crecimiento a diferentes rangos de $\mathrm{pH}$, salinidad y temperatura, además

\footnotetext{
${ }^{1}$ Grupo de investigación BIOARN, Universidad Politécnica Salesiana, Quito, Ecuador.

${ }^{2}$ Laboratorios de Ciencias de la Vida "CIVABI", Universidad Politécnica Salesiana, Quito, Ecuador.
} 
se realizó la determinación de tamaño, forma y posición de endospora de las cepas. Se desarrolló la extracción de ácidos nucleicos, utilizando el kit "High Pure Template Preparation Kit" de Roche ${ }^{\circledR}$ con la finalidad de analizar las curvas de amplificación mediante regiones específicas producto de la PCR en Tiempo Real.

\section{Materiales y métodos}

La investigación se llevó a cabo en los Laboratorios de Ciencias de la Vida de la Universidad Politécnica Salesiana Sede Quito, Campus el Girón con cepas bacterianas crio conservadas obtenidas del cepario del grupo de investigación Biotecnología Aplicada a los Recursos Naturales "BIOARN".

\section{Reactivación de cepas bacterianas}

El material biológico se obtuvo del Criobank codificado como BM (Bacillus megaterium) y BL (Bacillus licheniformis), cada perla se sembró en cajas Petri de $25 \mathrm{~mL}$ con medio Agar nutriente $(\mathrm{AN})$ a $30 \pm 2{ }^{\circ} \mathrm{C}$ por 24 horas $^{3}$.

\section{Resiembra de cepas}

De las placas Petri con crecimiento bacteriano se realizó la siembra con un asa de metal, las muestras se suspendieron con $7 \mathrm{~mL}$ de medio Tryptic Soy Broth (TSB) siendo sus condiciones óptimas de crecimiento de $30 \pm 2{ }^{\circ} \mathrm{C}$ y pH de $7 \pm 0,2$ en tubos de vidrio de $35 \mathrm{~mL}$ y con un tiempo de 24 horas $^{3}$.

\section{Caracterización microbiológica de cepas}

Se seleccionaron colonias blanquecinas, de bordes regulares que se resembraron en forma individual en Agar nutriente para determinar tamaño, forma bacilar y además se realizó tinción de Gram positiva y la tinción de endosporas ${ }^{4}$.

\section{Determinación de curvas de crecimiento}

Se realizaron curvas de crecimiento a cada uno de los cultivos de bacterias (BM y BL) durante 72 horas; esto con el objetivo de evaluar la capacidad de desarrollo de los microorganismos después de haber estado en contacto con los analitos ( $\mathrm{NaCl}, \mathrm{pH}$, temperatura). Se realizó 3 repeticiones con un total de 54 muestras. Para cada proceso se colocó $95 \mathrm{~mL}$ de caldo nutritivo (TSB) con $5 \mathrm{~mL}$ de inóculo (BM y BL) con un volumen final de $100 \mathrm{~mL}$. Se determinaron las temperaturas de $28^{\circ} \mathrm{C}$, $32{ }^{\circ} \mathrm{C}$ y $37^{\circ} \mathrm{C}$. En el caso de las curvas para $\mathrm{pH}$ se establecieron tres diferentes rangos: uno ácido de 5, uno neutro de 7 y un básico de 8. La salinidad se midió en tres porcentajes correspondientes a $2 \%, 4 \%$ y $6 \%$ de NaCl. Todos los ensayos se midieron mediante espectrofotometría mediante un lector de Elisa a una absorbancia de $495 \mathrm{~nm}$ cada dos horas, hasta llegar a un tiempo de 72 horas.

\section{Extracción de ácidos nucleicos}

Se colocó $200 \mu \mathrm{L}$ de muestra (BM y BL) en un tubo eppendorf libre de nucleasas de $1.5 \mathrm{~mL}$ agregando $5 \mu \mathrm{L}$ de lisozima e incubar 15 minutos a $37^{\circ} \mathrm{C}$. A continuación, se añadió $200 \mu \mathrm{L}$ de Buffer de Unión (Binding Buffer) y $40 \mu \mathrm{L}$ de Proteinasa K, se mezcló inmediatamente e incubó por 10 minutos a $70^{\circ} \mathrm{C}$.

Posterior a esto, se añadió $100 \mu \mathrm{L}$ de etanol absoluto al 99 \% y se mezcló bien; después, se pipeteó el contenido de la muestra en un Tubo con filtro (High Pure Spin Filter Tube) junto con un tubo colector, centrifugando por 1 minuto a $8000 \mathrm{xg}$ El residuo final en el tubo con filtro se procedió a lavar.

Para los lavados se armó un nuevo tubo colector, al cual se le añadió $500 \mu \mathrm{L}$ de Buffer removedor de inhibidores (Inhi- bitor Removal Buffer), centrifugando por 1 minuto a 8000 xg. Posterior a esto, se removió el tubo colector y se armó uno nuevo, se añadió $500 \mu \mathrm{L}$ de Buffer de lavado (Wash Buffer) centrifugando por 1 minuto a 8000 xg, este paso se lo realiza por duplicado.

Finalmente, para la elución del ADN se agregó $200 \mu \mathrm{L}$ de Buffer de elución (Elution Buffer). El ADN se conservó a - $20^{\circ} \mathrm{C}$ para su análisis posterior.

\section{Amplificación mediante PCR en Tiempo Real}

El protocolo que se estableció fue de $5 \mu \mathrm{L}$ para cada muestra (BM y BL) y sus controles. Se añadió $10,2 \mu \mathrm{L}$ de Agua grado Biología Molecular, 0,4 $\mu \mathrm{L}$ del Primer FW para BL ACTGAAGCGATTCGCAAGTT y para BM CGTGCAAGAGTGGGAAAAAT, 0,4 $\mu \mathrm{L}$ del Primer RW para BL TCGCTTCATATTGTGCGTTC y BM TCGCAATATGATCACGGCTA obtenidas de regiones específicas (lchAA) en el caso de B. licheniformis y (phaC) para $B$. megaterium. Para la elaboración de la Master Mix se utilizó el Kit LightCycle ${ }^{\circledR}$ Fast Start DNA MasterPLUS SYBR Green I.

\section{Análisis Estadístico}

Una estructura factorial permitió estudiar los efectos producidos por dos o más factores y sus interacciones. Los resultados previamente obtenidos sobre curvas de crecimiento a tres diferentes variables permitieron un análisis factorial de tratamientos, en este caso se seleccionó un diseño completamente al azar de $2 \times 3$ (correspondiente a 2 cepas y 3 niveles de un factor condicional, que corresponde a 6 tratamientos). La comparación de los resultados obtenidos se realizó mediante el test estadístico de ANOVA. Se calculó el área bajo la curva de crecimiento de la población bacteriana (ABCCP) acumulada en el tiempo ${ }^{5}$. Se compararon más de dos grupos entre sí, las diferencias entre éstos fueron determinadas con el test de Tukey y en todos los casos el límite de significancia fue fijado en $5 \%(p=0,05)^{6}$. Para el análisis de los datos se utilizó el programa estadístico Infostat 2018?.

\section{Resultados y discusión}

\section{Caracterización microbiológica de B. licheniformis y B. megaterium}

Las colonias correspondientes a BM fueron identificadas de forma macroscópica como colonias circulares, con borde entero y de elevación convexa. Según Pírez \& Mota $(2008)^{8}$, la tinción de gram corresponde a bacilos grampositivos. Se definió el tamaño en colonias grandes con una determinación microscópica de $560 \mu$ m. Para la tinción de endospora según Ñacato \& Valencia $(2016)^{9}$, se estableció endosporas muy visibles en posición terminal debido al gran tamaño de BM. La cepa $\mathrm{BL}$, presentó características macroscópicas como: colonias irregulares, borde ondulado y con elevación plana. Mediante observación microscópica se constató un tamaño de $116 \mu \mathrm{m}$. Se implementó la misma metodología señalada en BM para la tinción de endosporas obteniendo un bacilo grampositivo, con endosporas centrales.

\section{Curvas de crecimiento}

Se efectuó la curva de crecimiento microbiano de BM y BL por medio de ensayos espectrofotométricos y dos análisis estadísticos siguiendo la metodología antes mencionada con tres variables: temperatura, $\mathrm{pH}$ y salinidad. La cepa $\mathrm{BL}$ para la variable "temperatura" presentó una fase de adaptación entre las 0 y 10 horas, mientras que a partir de las 24 hasta las 48 
horas se da una fase de latencia, a las 72 horas a la temperatura de $32{ }^{\circ} \mathrm{C}$ fue la primera en decaer. La cepa BM en cuanto a la temperatura tuvo una etapa de adaptación muy parecida a la cepa $B L$, pero en la etapa exponencial la temperatura de $28{ }^{\circ} \mathrm{C}$ dio una diferencia ya que se encontró entre los valores más bajos, lo que indicó que no fue la temperatura óptima para su crecimiento, pero sin embargo si logra crecer a dichas condiciones. Según Tortoló-Cabañas \& Bell-García (2015)¹0, B. megaterium presenta buenos resultados de crecimiento entre las 45 y 48 horas. El pH en la cepa BL presentó una etapa de adaptación entre la hora 0 y 5; la fase exponencial se dio a partir de las 20 a las 48 horas notándose que a un pH de 5 se obtuvo el valor más alto. La hora de muerte se dio a las 72 horas siendo la curva de $\mathrm{pH} 5$ la primera en decaer. Mientras que la cepa BM no presentó diferencia en cuanto a un rango de $\mathrm{pH}$ que favoreciera su crecimiento ya que en los tres casos se desarrolló de forma similar, notándose una fase exponencial entre las 24 a 48 horas y la fase de muerte a las 72 horas. En congruencia con otros estudios ${ }^{11}$, se concluyó que el crecimiento celular de la cepa BL ocurría básicamente durante las primeras 24 horas. La salinidad se evidenció en la cepa BL con una fase de adaptación entre la hora 0 y 5, la fase exponencial se dio a partir de la hora 20 hasta la hora 60; la concentración de salinidad no influyó directamente en el crecimiento de BL ya que en los tres porcentajes de salinidad presentó un crecimiento sin diferencia significativa. La cepa BM tuvo una fase de adaptación entre la hora 0 hasta la hora 10 siendo la curva más alta de $4 \%$ de salinidad, en la fase exponencial se logró evidenciar que a una concentración baja se dio el mayor pico de crecimiento que corresponde al $2 \%$ de salinidad.

\section{Análisis estadístico factorial}

Se realizó un análisis factorial con tratamientos (tem- peratura, $\mathrm{pH}$ y salinidad) mediante la prueba de Tukey con $(p<0.05)^{6}$, este valor se tomó como referencia para determinar si existe o no diferencia significativa con horas clave (hora 0 , $5,24,48$, y 72). La variable "temperatura" a la hora 0 presentó una diferencia significativa en cuanto al crecimiento entre cepas, pero no se dio una interacción entre las tres temperaturas y tampoco se presentó una diferencia significativa para la interacción cepa*temperatura. No se presentó una interacción entre cepa*temperatura en ninguna de las horas establecidas lo que indicó que la temperatura no influye directamente en el crecimiento de estas cepas. Montor-Antonio y otros (2013) ${ }^{12}$, expresan que la cepa BL presenta una extensa aplicación en diversos procesos industriales debido a sus amplios rangos de operación de temperatura $\left(25-90{ }^{\circ} \mathrm{C}\right)$. La variable "pH" obtuvo una interacción cepa* $\mathrm{pH}$ que denotó claramente que la cepa BM forma un solo grupo, sin diferencia en el crecimiento de los valores de $\mathrm{pH}$ y en el caso de la cepa BL se notó la diferencia que existe entre los valores de $\mathrm{pH} 7$ y 8 . Según, Pérez y otros $(1998)^{13}$ el crecimiento de Bacillus está muy influenciado por el pH.

\section{Análisis estadístico de área bajo la curva}

El área bajo la curva arrojó resultados que se pueden observar en la Tabla 1. Para la variable "temperatura" existió una diferencia significativa entre cepas y en los tres valores establecidos no se encontró diferencia alguna ya que los tres se asignaron en un mismo grupo, es decir la temperatura no influyó directamente en el crecimiento de estas cepas. En cuanto a la variable "pH" si existió una diferencia significativa entre cepas siendo la cepa BL la que tuvo mayor crecimiento y en cuanto a los valores específicos $(5,7,8 \mathrm{pH})$ es notable que a un $\mathrm{pH}$ de 8 ésta tuvo mejores resultados, además se dio una diferencia significativa para la interacción cepa* ${ }^{\star} \mathrm{H}$ en la cual

\begin{tabular}{|c|c|c|c|}
\hline & BM & BL & p-valor \\
\hline CEPA & $9107.05 \pm 25.85 b$ & $8848.98 \pm 25.85 \mathrm{a}$ & $<0.0001$ \\
\hline \multirow{3}{*}{ TEMPERATURA } & 28 & $8915.83 \pm 31.65 \mathrm{a}$ & \multirow{3}{*}{0.08483} \\
\hline & 32 & $8996.55 \pm 31.65 \mathrm{a}$ & \\
\hline & 37 & $8915.83 \pm 31.65 \mathrm{a}$ & \\
\hline CEPA & $6802.81 \pm 23.79 a$ & $6962.28 \pm 23.79 \mathrm{~b}$ & 0.0005 \\
\hline \multirow{3}{*}{ pH } & 5 & $6982.16 \pm 29.13 b$ & \multirow{3}{*}{0.0001} \\
\hline & 7 & $6947.37 \pm 29.13 b$ & \\
\hline & 8 & $6718.10 \pm 29.13 \mathrm{a}$ & \\
\hline CEPA* $\mathrm{pH}$ & $\mathrm{BM}$ & BL & \\
\hline 5 & $7005.48 \pm 41.20 \mathrm{~b}$ & $6958.84 \pm 41.20 \mathrm{~b}$ & \multirow{3}{*}{$<0.0001$} \\
\hline 7 & $6996.01 \pm 41.20 \mathrm{~b}$ & $6898.73 \pm 41.20 \mathrm{~b}$ & \\
\hline 8 & $6406.95 \pm 41.20 \mathrm{a}$ & $7029.25 \pm 41.20 \mathrm{~b}$ & \\
\hline CEPA & $5499.35 \pm 10.19 \mathrm{a}$ & $5549.12 \pm 10.19 \mathrm{~b}$ & 0.0048 \\
\hline \multirow{3}{*}{ SALINIDAD } & 2 & $5594.52 \pm 12.47 \mathrm{c}$ & \multirow{3}{*}{$<0.0001$} \\
\hline & 4 & $5523.86 \pm 12.47 \mathrm{~b}$ & \\
\hline & 6 & $5454.31 \pm 12.47 \mathrm{a}$ & \\
\hline CEPA $\approx$ SALINIDAD & $\mathrm{BM}$ & BL & \\
\hline 2 & $5620.08 \pm 17.64 \mathrm{~d}$ & $5568.95 \pm 17.64 \mathrm{~cd}$ & \multirow{3}{*}{0.0012} \\
\hline 4 & $5477.64 \pm 17.64 \mathrm{ab}$ & $5570.09 \pm 17.64 \mathrm{~cd}$ & \\
\hline 6 & $5400.31 \pm 17.64 \mathrm{a}$ & $5508.31 \pm 17.64 \mathrm{bc}$ & \\
\hline
\end{tabular}

Tabla 1. Valores de medias, error experimental y $(p)$ del análisis de área bajo la curva para las variables "Temperatura, pH y Salinidad" de las cepas BM y BL. 
se formaron claramente dos grupos entre las dos cepas de los cuales solo BM a un pH de 8 tuvo diferencia alguna. Para la variable "salinidad" se dio una diferencia significativa entre cepas notándose que la cepa BL es la que presenta mayor crecimiento y para los valores específicos $(2,4,6 \%)$ existió diferencia significativa entre las tres concentraciones de salinidad en el caso de las dos cepas. También existió diferencia para la interacción cepa*salinidad siendo la cepa BM la que presentó una diferencia entre las dos a una concentración del $6 \%$ de NaCl.

\section{Identificación molecular de B. licheniformis y B. megaterium mediante PCR en Tiempo Real}

La cepa BM y BL fueron sometidas a estudio mediante la técnica PCR en Tiempo Real; en la Figura 1 se muestran los productos de amplificación de la cepa BL mientras transcurren los ciclos de la PCR. La cepa BL presentó una hibridación con los primers codificados utilizados en otros estudios ${ }^{14}$, que permitieron la amplificación del gen lchAA región que ha demostrado ser capaz de identificar de forma taxonómica a esta cepa ya que el operón de Lichenysin (lchA) es responsable de la síntesis de lichenysin en $B$. licheniformis y se confirmó la cepa BL correspondiente a Bacillus licheniformis. Además, se observan los resultados obtenidos en la amplificación de la cepa BM en la cual se da la hibridación del ADN molde mediante los cebadores específicos utilizados en estudios previos ${ }^{15}$, que permitieron la amplificación del gen phaC cuyas secuencias sirven para reconocer regiones únicas presentes, que fueron utilizadas para diseñar los cebadores indicando la singularidad de las secuencias de phaC en la identificación de B. megaterium. Con estos resultados se pudo confirmar la cepa BM como $B$. megaterium.

Existen estudios como el de Konzl (1997) ${ }^{16}$, que presenta a la PCR en Tiempo Real como la técnica adecuada para la caracterización molecular de genes de la bacitracina producido por B. licheniformis. Dado que los miembros del género bacteriano gram positivo Bacillus son bien conocidos por su potencial para secretar un número de enzimas de interés, no fue sorprendente que las cepas de estudio correspondientes a $\mathrm{BL}$ y $\mathrm{BM}$ aisladas mediante cebadores específicos, resultaron ser miembros de este taxón. B. licheniformis es una bacteria que se puede aislar de varias fuentes: como el suelo, el agua y en los desperdicios ${ }^{17}$. En el caso de la cepa BL, este estudio se basó en la amplificación del gen lchAA para su identificación molecular, existe un estudio que ha demostrado que la cepa $B$. licheniformis ATCC 14580 y algunas otras cepas de B. licheniformis albergan el gen lchA $A^{17}$.

Existen varios estudios implicados en la identificación de la cepa BM, este estudio se centró específicamente en el gen phaC. Algunos autores como Pramoda \& Ajeet (2013) ${ }^{15}$ proponen utilizar el gen polihidroxialcanoato sintasa $C$ de B. megaterium para el diseño de cebadores que amplifican la región phaC para su identificación. Por otra parte Chen (1991) ${ }^{18}$ informa que muchas especies de Bacillus producen pha y desde entonces el gen para la síntesis de pha ha sido clonado a partir de B. megaterium.

\section{Conclusiones}

Las concentraciones bacterianas obtenidas mediante la técnica McFarland permitieron generar las curvas de crecimiento para establecer las horas clave en el análisis, confirmando que las características analizadas: forma, tamaño, tinción de gram y posición de endospora corresponden a especies pertenecientes a la familia Bacillaceae. Los modelos estadísticos ANOVA y Tukey permitieron el análisis particionado de los componentes para aprobar la hipótesis y con el análisis del área bajo la curva se concluye que los datos obtenidos frente a las variables planteadas presentan un alto grado de precisión. Finalmente la técnica molecular de PCR en Tiempo Real mediante las curvas de amplificación ${ }^{19}$, permitió confirmar la presunción bioquímica de la cepa BM que corresponde a Bacillus megaterium mediante el análisis de la región phaC; además se pudo corroborar que la cepa $\mathrm{BL}$ corresponde a Bacillus licheniformis al analizar la región lchAA.

\section{Acknowledgements}

A la Ing. Alejandra Medrano por su apoyo en la Investigación.
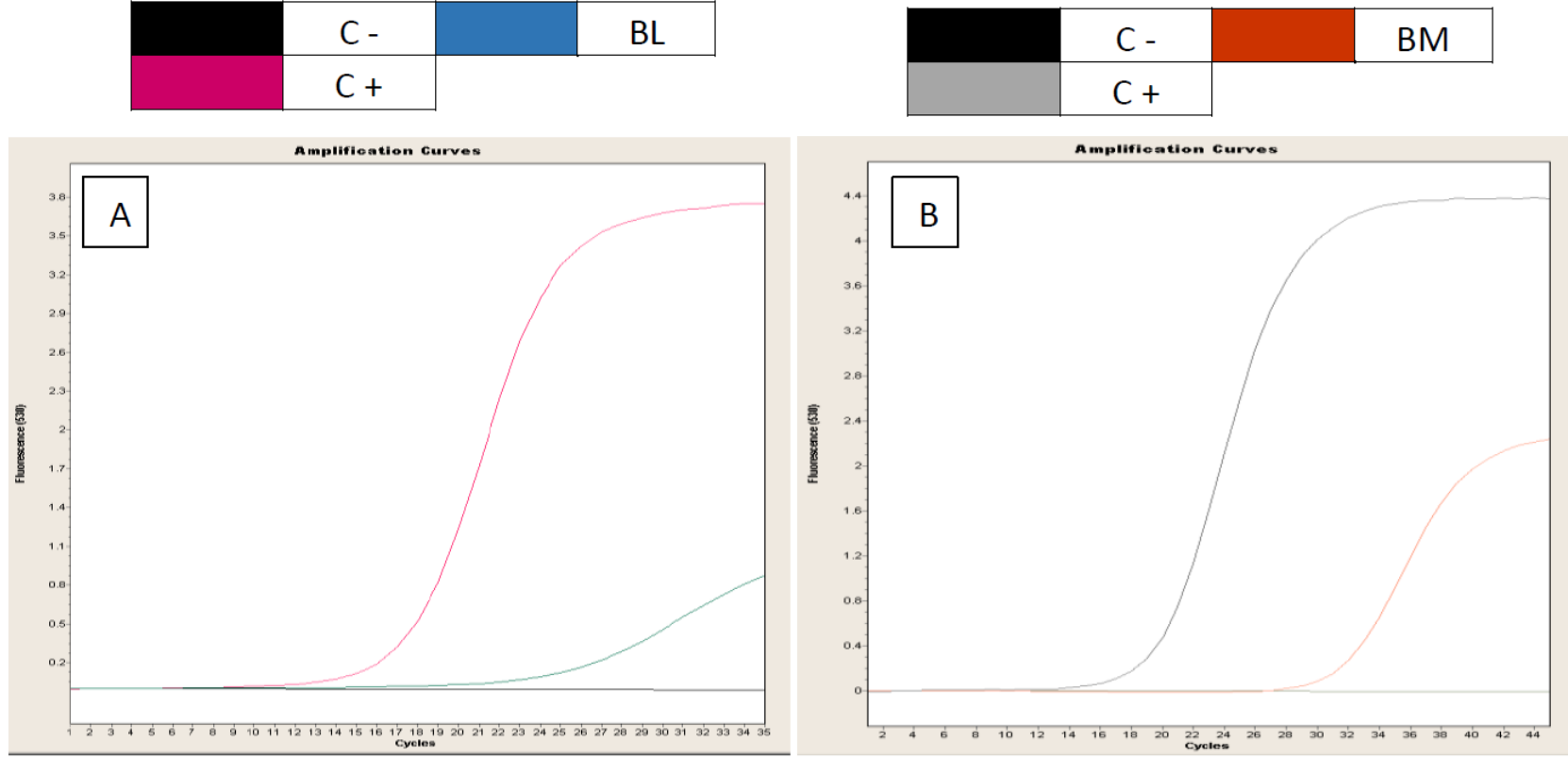

Figura 1. A) Curva de amplificación PCR en Tiempo Real con SYBR Green de la cepa BL: fluorescencia vs ciclos. C-: control negativo; C+: Bacillus licheniformis ATCC ${ }^{\circledR}$ 14580. B) Curva de amplificación PCR en Tiempo Real con SYBR Green de la cepa BM: fluorescencia vs ciclos. C-: control negativo; C+: Bacillus megaterium ATCC ${ }^{\circledR}$ 14581. En equipo PCR LightCycler ${ }^{\circledR} 2.0$. 


\section{Referencias bibliográficas}

1. Macedo M. Temas de Bacteriología y Virología Médica [Internet]. Montevideo: Universidad de la República; 2008. 646 p. Available from: http://www.enfermeriaaps.com/portal/?wpfb $d l=4348 \% 0$ Ahttp://www.higiene.edu.uy/cefa/2008/enterovirus pdf

2. Sosa-López A, Álvarez-Rivera V, Torres-Campos D, Casadesús-Romero L. Identificación y caracterización de seis aislados pertenecientes al género Bacillus promisorios para el control de Rhizoctonia solani Künh y Sclerotium rolfsii Sacc. Fitosanidad. 2012;15(1):39-43

3. Egas C, Tinajero M. Aislamiento de microorganismo capaces de producir antibióticos, a partir de suelos de Regiones Naturales del Ecuador [Internet]. Tesis. Universidad Politécnica Salesiana; 2016. Available from: http://dspace.ups.edu.ec/bitstream/123456789/5081/1/UPS-CYT00109.pdf

4. Reyes A, Ruiz E, Yam C, Dzul M. Selección De Bacillus Spp . Con Actividad Antagón Goid. En Diferentes Medios De Cultivo. Fitosanidad [Internet]. 2011;15(2):112-21. Available from: https:// www.redalyc.org/articulo.oa?id=2091/209122297007

5. Cecilia B, Gustavo G, Guillermo G, Alejandra B. Componentes de resistencia a Xanthomonas vesicatoria raza T2 en genotipos de tomate en condiciones de invernadero y cámara de crecimiento. Agrociencia Uruguay. 2014;18(1):86-96.

6. Giacomino N, Notaro U, Cerra M, Gumiy D, Stiefel S, Baroni E, et al. Actividad antibacteriana in vitro de Cefalexina sobre Escherichia coli en suero y orina de canino. FAVE Sección Ciencias Vet. 2014;11(1/2):15-30.

7. Balzarini M, Gonzalez L, Tablada M, Casanoves F, Di Rienzo J, Robledo C. Infostat: manual del usuario. Córdoba: Editorial Brujas. Brujas; 2008.

8. Pírez M, Mota M. Morfología y Estructura Bacteriana. In: TEMAS DE BACTERIOLOGÍA Y VIROLOGÍA MÉDICA. 2008. p. 48-60.

9. Ñacato C, Valencia M. Aislamiento, identificación y pruebas in vitro de cepas autóctonas de Bacillus subtilis como agente de biocontrol de Alternaria spp en Brassica oleracea var. Itálica. [Internet]. Tesis. Universidad Politécnica Salesiana; 2016. Available from: http://dspace.ups.edu.ec/bitstream/123456789/5081/1/ UPS-CYT00109.pdf
10. Tortoló-cabañas K, Bell-garcía A. Producción de proteínas recombinantes en Bacillus megaterium: estado del arte. ICIDCA Sobre los Deriv la Caña Azúcar [Internet]. 2015;49(1):22-6. Available from: https://www.redalyc.org/articulo.oa?id=2231/223136961004

11. Cascante J. Fermentación de bacterias del género Bacillus en altas concentraciones de oxígeno. J Chem Inf Model. 2013;53(9):1689-99.

12. Montor-Antonio J, Olvera-Carranza C, Reyes-Duarte D, Sachman-Ruiz B, Ramírez-Coutiño L, Del Moral S. Biochemical characterization of AmiJ33 an amylase from Bacillus amyloliquefaciens isolated of sugarcane soils at the Papaloapan region Revista Electrónica Nova Scientia Caracterización bioquímica de AmiJ33 , una amilasa de Bacillus amyloliquefaciens. Nov Sci. 2013;6(12):39-59.

13. Gonzalez RA, Pérez M, Florido G, Piad R, González G, Sol G. Isolation and characterization of strains of Bacillus spp. Production of proteolytic enzymes for the production of protein hydrolysates. Rev Av Científica. 1998 Jan 1;1:2-9.

14. Madslien EH, Rønning HT, Lindbäck T, Hassel B, Andersson MA Granum PE. Lichenysin is produced by most Bacillus licheniformis strains. J Appl Microbiol. 2013 Oct;115(4):1068-80.

15. Nayak PK, Mohanty AK, Gaonkar T, Kumar A, Bhosle SN, Garg S. Rapid Identification of Polyhydroxyalkanoate Accumulating Members of Bacillales Using Internal Primers for phaC Gene of Bacillus megaterium. ISRN Bacteriol. 2013;2013:1-12

16. Konzl D, Klensl A, Schbrgendorfe K, Marahiell M. The bacitracin biosynthesis operon of Bacillus licheniformis ATCC 10716: molecular characterization of three multi-modular peptide synthetases. Chem Biol [Internet]. 1997 [cited 2019 Dec 2];4(12):27-37. Available from: https://www.ncbi.nlm.nih.gov/pubmed/9427658

17. Waldeck J, Daum G, Bisping B, Meinhardt F. Isolation and molecular characterization of chitinase-deficient Bacillus licheniformis strains capable of deproteinization of shrimp shell waste to obtain highly viscous chitin. Appl Environ Microbiol. 2006;72(12):7879-85.

18. Chen G. Occurrence of poly-D(-)-3-hydroxyalkanoates in the genus Bacillus. FEMS Microbiol Lett. 1991 Nov 15;84(2):173-6.

19. Chiluisa-Utreras V, Echeverría A. Identificación y cuantificación de Salmonella sp. y ADNr 16S bacteriano mediante PCR en tiempo real en muestras de alimentos. BIONATURA. 2017; 1-6.

Received: 31 Enero 2020

Accepted: 4 Abril 2020 